\title{
GLASS - STEEL HYBRID ELEMENTS UNDER FOUR POINT BENDING TEST
}

\author{
Bojana Trajanoska* \\ University in Skopje "Ss. Cyril and Methodius", Faculty of Mechanical Engineering, Skopje, Macedonia \\ Dr Viktor Gavriloski \\ University in Skopje "Ss. Cyril and Methodius", Faculty of Mechanical Engineering, Skopje, Macedonia \\ Dr Zoran Bogatinoski \\ University in Skopje "Ss. Cyril and Methodius", Faculty of Mechanical Engineering, Skopje, Macedonia \\ Filip Zdraveski \\ University in Skopje "Ss. Cyril and Methodius", Faculty of Mechanical Engineering, Skopje, Macedonia
}

Problems evolving from the brittleness of structural glass result in need of innovative solutions which will improve the post-breakage behaviour of the elements in the structure. As the need of the glass performance gets higher, the fully tempered glass gets in the focus and its usage becomes greater. But although this type of glass gives great performance with its tensile strength and deflection capaciy, it has no residual strength. Due to its breakage pattern into small pieces the collapse of the element may be instant even in laminated glass elements. Thus, increasing the post breakage behaviour is crucial in order to keep the integrity of the tempered glass element. This can be done either by changing the interlayer properties, or including kind of reinforcement in the element structure. This paper presents experimental testing of the performances of steel plate reinforced hybrid glass element under four point bending test. As a result, it shows the improvement in mechanical behaviour of the described hybrid structure concept compared to a monolithic glass element with same dimensions, by means of stress distribution and reinforcement capacity.

Key words: Hybrid elements, Steel reinforcement, Post breakage, Experimental testing, Stress distribution

\section{INTRODUCTION}

Glass elements become part of the structures when the first glass production line has been established. Today though, not only as infill elements but more recently part of the bearing structures. Its main disadvantage of being extremely brittle material is partly solved by laminating in two or more plies of glass. This process is used for achieving required structural thickness and residual strength after breakage of one or more laminates. In a way, with laminating, glass gets ductility which is governed by the interlayer material $[01,09]$.

The demand for high structural performance due to the increasing size of glass panes and all-glass structures has led to frequent use of fully tempered glass, characterized by its high tensile strength. However, fully tempered glass has almost no residual strength even if used in laminated glass units. This is due to its fracture pattern, the breaking up into small fragments and the low stiffness and strength of the inter- layer materials currently used in laminating. The behaviour of the laminated structure is directly influenced by the interlayer properties. These influences on interlayer properties are especially important in cases when whole laminated pane breaks and total collapse occurs. In order to achieve high residual strength i.e. post breakage capacity, interlayer has to possess high tensile strength, high extensional stiffness, high elongation at rupture and good adhesion [04].

When using tempered glass usually the laminate consists of more than two plies in order to guarantee residual strength of the element. This results in increasing the total weight of the laminated element which.

The concept of reinforcing the element structure with additional layers is proposed and tested by several researchers. Feirabend $S$., in his research [03] analyses a hybrid laminated structure that includes a perforated steel layer functioning as reinforcement between glass panes where the bond is made using common laminat- 
ing interlayer (PVB). In this research experimental testing of the residual capacity gained with the new structure under four point bending on different temperatures considering the influence on the interlayer properties in these conditions is presented.

Nhamoinesu S. in [05] gives a different approach of reinforcing where the reinforcement consists of steel profile adhesively bonded to the edges of the glass panes in different concepts, between two panes using the logic of sandwich structure, and in a concept of one glass pane with bonded profiles in the tension zone of the glass element. With this research the post breakage behaviour of the elements under out of plane bending using different types of adhesives and different model scales is evaluated.

This way of introducing new hybrid structures and evaluating their main advantage of post breakage capacity and stress distribution change, is conduct by Weller B. In [08] he presents results obtained by testing hybrid beam and plate elements reinforced with different steel and polycarbonate additions in order to determine their mechanical characteristics under bending.

In this paper a way of achieving post breakage capacity and desirable stress state of a tempered glass element is shown, by forming new hybrid laminated glass to steel structure. The mechanical characteristics of the models gain by the proposed concept are experimentally tested and evaluated.

\section{HYBRID ELEMENT CONCEPT}

New concept of glass - steel elements is proposed consisting tempered glass panel and thin steel layer which form a laminated structure where the bond between laminates is made by means of adhesive and not the usual interlayer polymer materials.

The laminate structure is made of thin perforated metal layer located at the tensile zone of the glass panel bonded with adhesive along the surface of the glass panel. In this way, the reinforcement is achieved in the weakest zone of the panel where tensile stresses occur under out of plane bending.

With the formed structure the load is distributed to the elasto-plastic perforated steel sheet that has a capacity of accepting higher stresses than the glass. On the other hand, reinforcing the element in this manner decreases its overall weight compared to the laminated glass structures since only one glass pane is included.

Using a perforated metal sheet the concept offers reinforcement of the glass element, residual strength and redistribution of the principle stresses in the panel, and at the same time preserving the transparency of the glass. In addition, different perforation geometries may be used for the reinforcement allowing for various reinforcement capacities [06]. In this paper a unified perforation of parallel grid of circle forms is used for the models and experimentally is evaluated its reinforcement capacity.

The used glass pane in the hybrid models is made of fully tempered glass with experimentally defined bending strength of $200 \mathrm{MPa}$. The other two glass characteristics relevant for this testing are its Young's modulus of $70000 \mathrm{MPa}$, which does not change with the glass thermal treatment, and Poisson's coefficient of 0,22 . The steel reinforcement used in the models is made of stainless steel with tensile strength of a 550 $\mathrm{MPa}$. The surface bond to the metal layer to the glass panel is made by structural adhesive type DC3145 which is silicon based. Its characteristics are provided by the manufacturer and for this testing were not experimentally confirmed. The used surface type of bonding allows for laminate effect of the structure and ensures composite action.

\section{EXPERIMENTAL SETUP}

In order to determinate the mechanical characteristics of the hybrid elements, an experimental testings are done in accordance to EN 12883:2000 [02]. This standard defines the four point bending testing (Figure 1) of flat glass panes for evaluating bending strength of the elements.

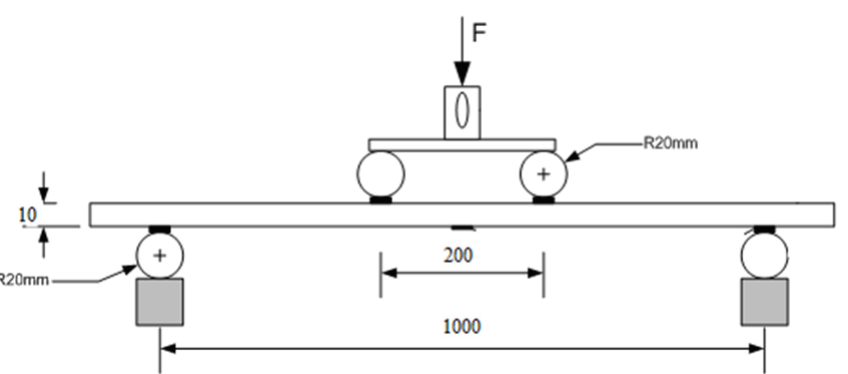

Figure 1: Experimental setup of four point bending

The testing is done using an universal material testing machine ZWICK ROELL Z250 which has a maximum load capacity of $250 \mathrm{kN}$. Additionally, KYOWA deflection measuring device was used 
with maximum $100 \mathrm{~mm}$ extension, and in order to defining the stress state of the panel, strain gages were used located at the tension and compression zone of the models (Figure 2). In this way a possible delamination occurring during testing could be detected that indicates the capacity of composite action of the structure.

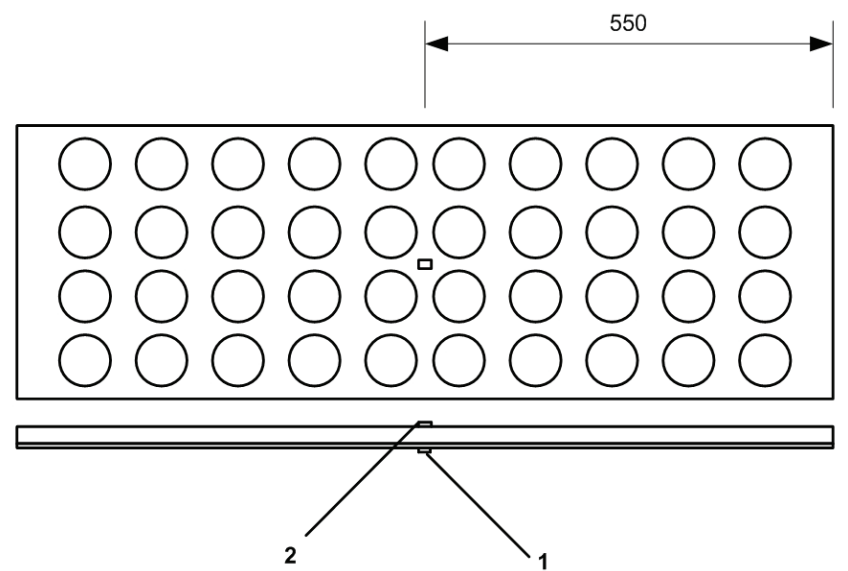

Figure 2: Strain gage location 1. Tension zone 2.

Compression zone

Two different types of models were used during the testing. At first, flat glass panes with the defined dimensions were tested, for evaluating the bending stiffness of a single tempered glass pane. The tested models named BG.10 had dimensions of $1100 \mathrm{~mm}$ in length and $300 \mathrm{~mm}$ in width with constant thickness of $10 \mathrm{~mm}$. Considering probability for surface flaws that can influence the strength of the element, several specimens where tested [07].

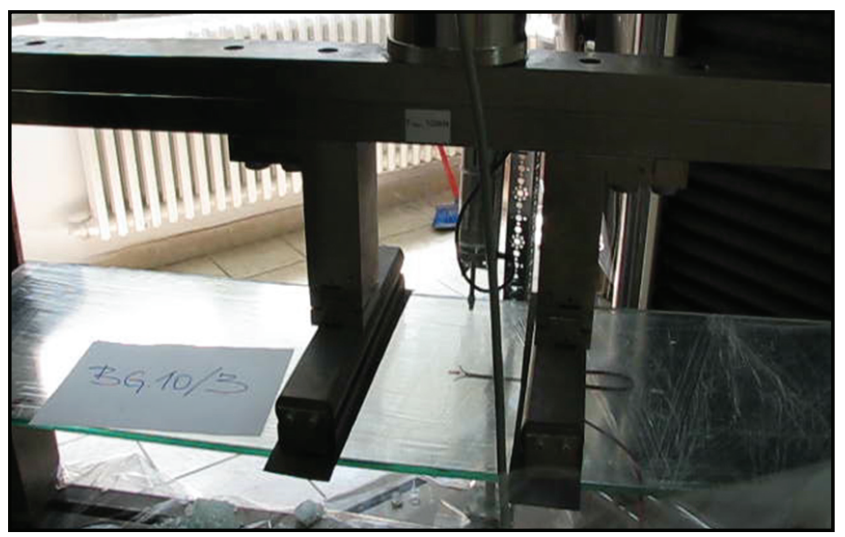

Figure 3: Setup of glass specimen prior loading

The applied reinforcement has the same dimensions and a thickness of $1 \mathrm{~mm}$. The distance between the support rollers of the machine was $1000 \mathrm{~mm}$ and the distance between the loading rollers set $200 \mathrm{~mm}$.
Figure 3 shows the set-up for these models before applying the out of plane load. The hybrid elements named BSG.40_10 consisting of glass panel with bonded reinforcement, were tested as a second part of the testing.

The testing is done under constantly increasing out of plane load, which according to the standard allows increasing of the stress not more than $2 \pm 0,4 \mathrm{MPa} / \mathrm{sec}$, until the full collapse of the specimen.

A perforated reinforcement layer with unified circle forms of $40 \mathrm{~mm}$ in circle diameter was used for forming the models. As shown in figure 4, the set-up and testing conditions of the hybrid models were the same as for glass specimens tested previously.

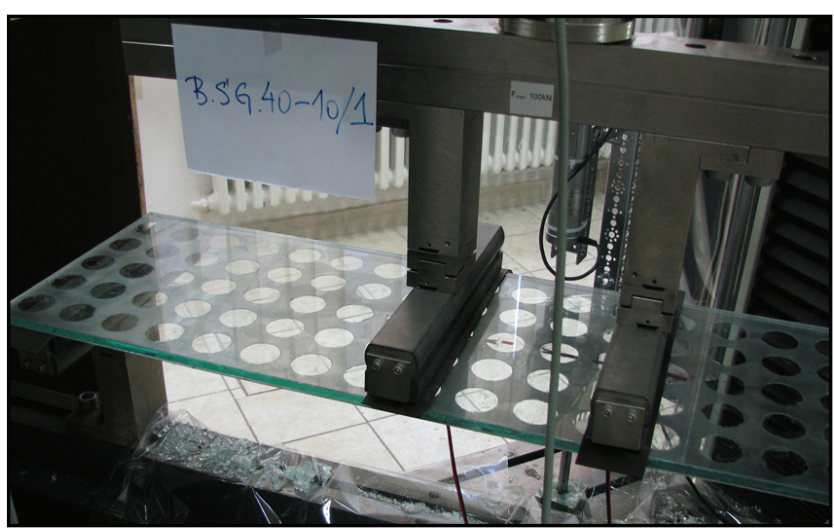

Figure 4: Setup of hybrid model specimen prior loading

\section{RESULTS}

The standard used for the experimental testing defines the bending strength of the tested element by means of the maximal force of failure for the glass elements, and force at first crack for the hybrid elements. Thus, as results of this experimental testing a force deflection curves were gained and analysed for the tested models.

Since multiple specimens by model were tested, interpolated summery curves were defined to represent the force deflection characteristic of the elements. In Figure 4, the characteristic diagram of monolithic glass is given. The failure load of the element and the maximal deflection prior this failure, are noted. The testing shows maximal force of near $5,7 \mathrm{kN}$ for a deflection of $50 \mathrm{~mm}$. 


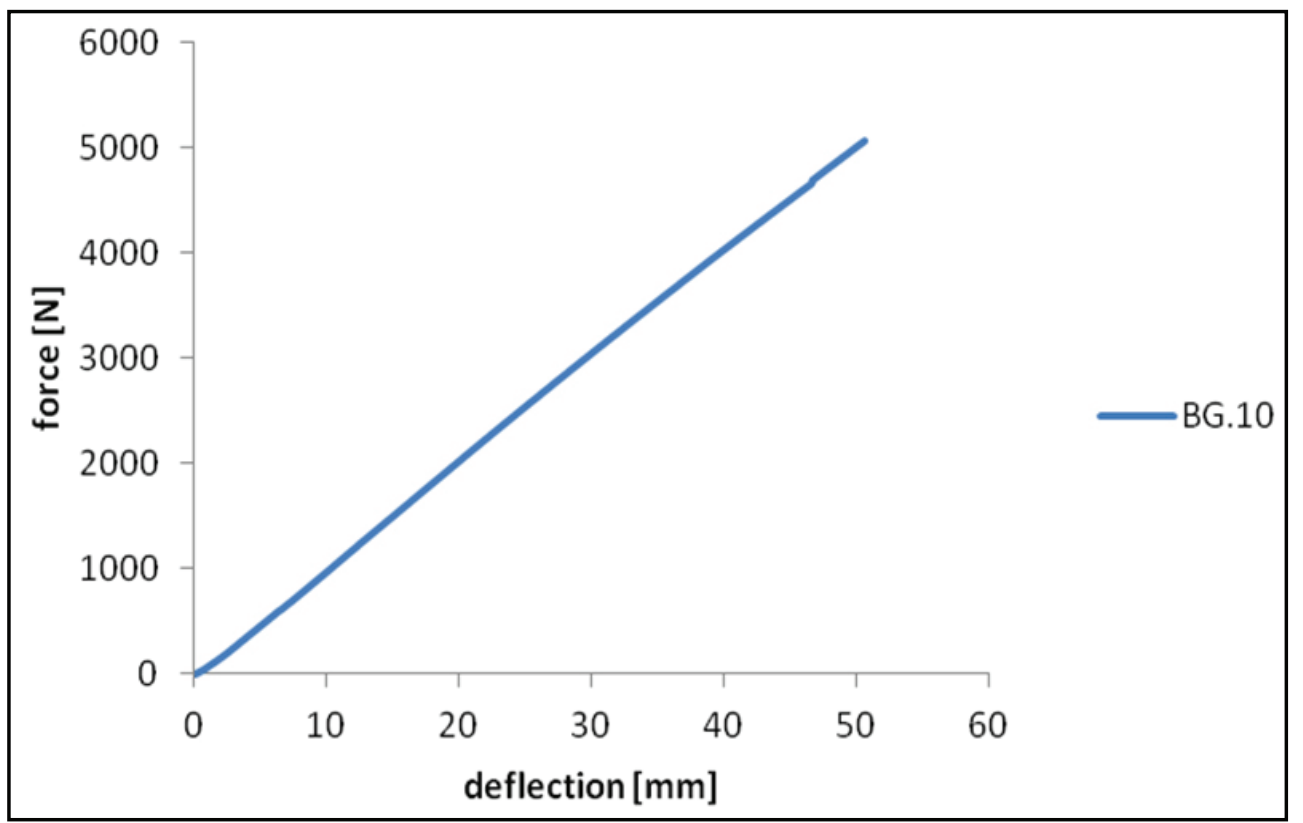

Figure 4: Force deflection characteristic for glass pane $(h=10 \mathrm{~mm})$

The force deflection diagrams for the hybrid models with perforation of $40 \mathrm{~mm}$ are presented in Figure 5, where the post breakage behaviour can be analysed. The curves evidently show existent residual strength since the force magnitude increases again after the appearance of first crack.
The forming of the hybrid models was done manually and different flaws in the connection were expected which may influence the composite action of the structure thus compromise the overall stiffness and strength. By this mean, multiple specimens were tested in order to get more reliable results shown in Table 1.

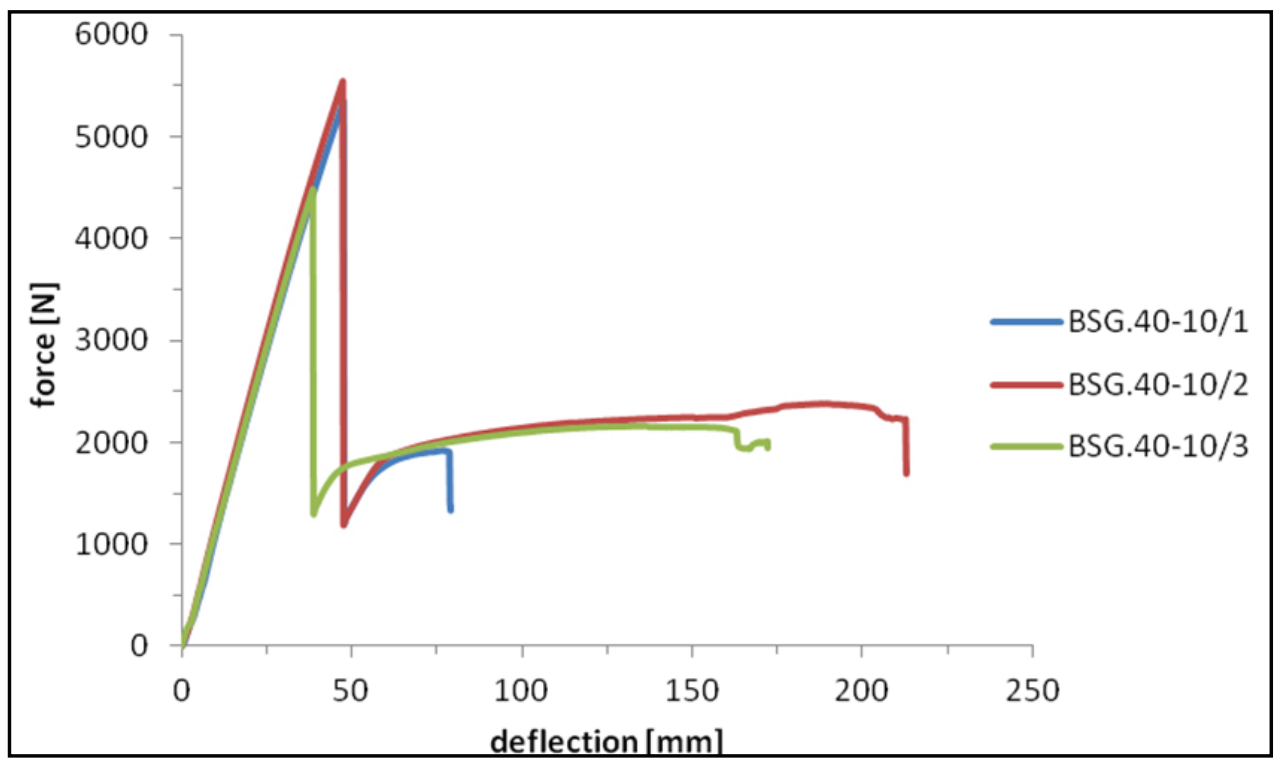

Figure 5: Force deflection curves for hybrid models $(d=40 \mathrm{~mm})$

As for the influence of the perforation layer, it can be observed that the $40 \mathrm{~mm}$ holes perforation provides certain post breakage capacity which opposites the glass brittleness. This can be con- cluded not only considering the maximal force that is reached but also the total deflection of the models prior collapse. 
Table 1: Test results for the hybrid models

\begin{tabular}{|c|c|c|c|}
\hline Specimens & Failure load at first crack [N] & Deflection [mm] & Stress in glass panel [MPa] \\
\hline BSG.40-10/1 & 5357.2 & 47.5 & 159.3 \\
\hline BSG.40-10/2 & 5550.4 & 47.4 & 158.1 \\
\hline BSG.40-10/3 & 4480.5 & 38.6 & 128.6 \\
\hline
\end{tabular}

Figure 6 presents the influence of the applied reinforcement on the mechanical behaviour of the models. The biggest influence of the reinforcement layer is on the overall stiffness of the el- ements, as it can be noticed that the maximal force of failure reached by monolithic glass elements is achieved over smaller deflection by the hybrid elements.

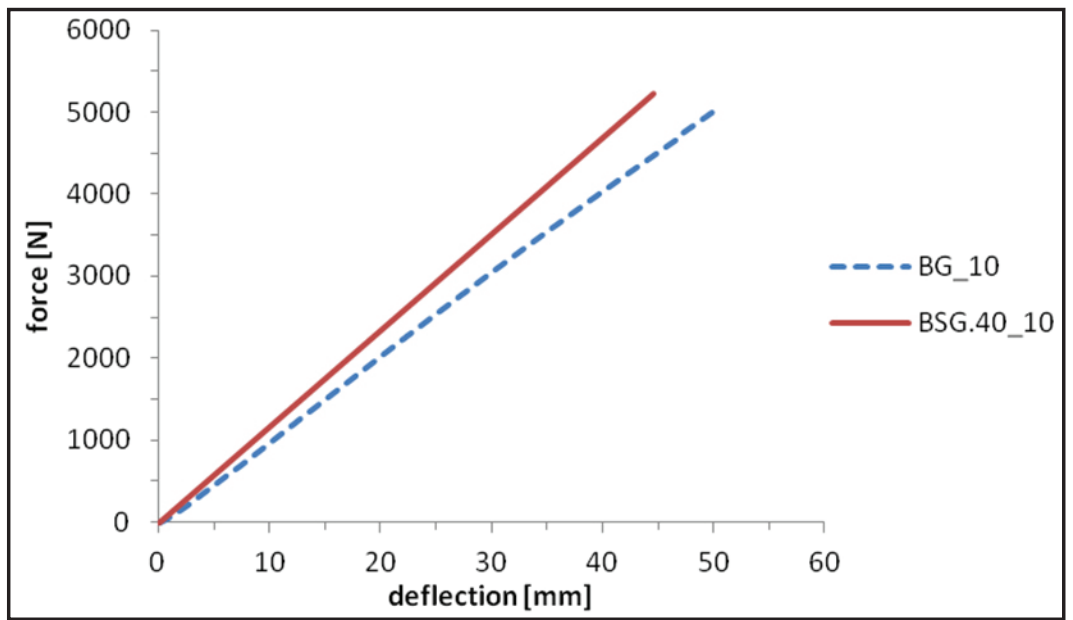

Figure 6: Comparative results of the tested models

According to the assumptions made at the beginning, the proposed concept of the hybrid elements should allow for stress redistribution in the glass panel and decreased magnitude of the principle stress measured in its tension zone. The analytical solution of the geometric properties of the cross section shows doubled section modulus of the hybrid element compared to the single pane glass element with the same thickness. But, this analysis is done over an ideal cross section of a composite with implied full composite action. Since the hybrid elements are made of three different construction materials having divergent mechanical characteristics, the capacity of composite action cannot be predicted. Thus, by this experimental test for measuring the stress magnitude in the glass panel, the mentioned attribute of the hybrid structure can be evaluated. Table 2 presents the results of the stresses in the glass element where maximum loading moment occurs compared to analytical solution.

Table 1: Test results for the hybrid models

\begin{tabular}{|c|c|c|c|c|}
\hline \multirow{2}{*}{ Force (load) [N] } & \multicolumn{2}{|c|}{ Single glass pane } & \multicolumn{2}{c|}{ Glass pane in hybrid el. } \\
\cline { 2 - 5 } & $\begin{array}{c}\text { Stress [MPa] } \\
\text { Analytical }\end{array}$ & $\begin{array}{c}\text { Stress [MPa] } \\
\text { Experimental }\end{array}$ & $\begin{array}{c}\text { Stress [MPa] } \\
\text { Analytical }\end{array}$ & $\begin{array}{c}\text { Stress [MPa] } \\
\text { Experimental }\end{array}$ \\
\hline \hline 1000 & 40 & 43 & 20.7 & 24 \\
\hline 2000 & 80 & 82 & 41.45 & 53 \\
\hline 3000 & 120 & 117 & 62.18 & 81 \\
\hline
\end{tabular}

The results of the experiment show deviation compared to analytical analysis of the stress state of the glass panel, especially under higher load magnitude, indicating that the hybrid elements do not reach full composite action. On the other hand, the analytical solution takes in consideration constant section modulus of the hybrid element which is not case with the proposed concepts since the reinforcement layer is perforated. But, from the presented results one may still observe decreasing of the principle stresses in the glass panel under the same load as a result of the added reinforcement layer. 


\section{CONCLUSION}

From this research it may be concluded that tempered glass has no residual strength which is crucial when used in structural elements and it breaks suddenly after reaching the maximum bending strength. Another possible approach of solving the problem of post breakage behaviour is applying reinforcement which has a ductile properties not influenced from time and temperature as polymer interlayers. Steel is this kind of material, which is used for forming hybrid glass elements concepts in form of laminated structures. These hybrid elements are using the mechanical characteristics of a perforated steel layer with small thickness of $1 \mathrm{~mm}$ to act as reinforcement layer giving residual strength to a tempered glass panel by means of adhesive bonding to the glass elements tension zone and at the same time not compromising the overall transparency of the glass. Even though only $1 \mathrm{~mm}$ thick reinforcement layer is applied, the glass element gets post breakage capacity and greater stiffness under out of plane loading. The influence of the perforation dimension is analysed by experimental testing concluding that the reinforcement layer having perforation with 40 $\mathrm{mm}$ holes in diameter gives considerable residual strength capacity on $10 \mathrm{~mm}$ thick tempered glass panel forming a hybrid element which offers greater structural integrity compared to the brittle monolithic glass element. Regarding the stress state of the panel, the process of reinforcing the structure results in redistribution of the stresses in the tempered glass in its weakest zone under out of plane bending, while at the same time decreasing the value of the maximum principle stress.

\section{REFERENCES}

1) Belis, J., Van Impe, R., Vanlaere, W., Lagae, G. Buffel, P. and M. De Beule (2004): Glass Structures and Plasticity: Contradiction or Future?, Key Eng. Mater., vol. 274-276, pp. 975-980.

2) EN 1288-3:2000. Glass in building - Determination of the bending strength of glass - Part 3:Test with specimen supported at two points (four-point bending) CEN,2000

3) Feirabend, S. and Sobek, P. W.(2009): Improved post-breakage behavior of laminated glass due to embedded reinforcement, Glass performance days 2009, pp. 726-729.

4) Haldimann, M., Luible, A. and Overend, M.(2007): Structural use of Glass

5) Nhamoinesu, S.(2014): Steel-Glass Composite Structures (thesis)

6) O. Marina, O., Trajanoska, B. and Filipovska, E.(2014): Parametrically generated geometry of the glass metal reinforcement layer, Challenging Glass 4 \& COST Action TU0905 Final Conference.

7) Veer, F. (2007): The strength of glass, a nontransparent value, Heron, vol. 52, no. 1-2, pp. 87-104.

8) Weller, B.,Weimar, T., Härth, K.(2009): Hybrid Components of Glass and Polycarbonate, Glass performance days, pp. 144-148.

9) Wurm, J. A. N.(2007), Glass Structures, Basel: Birkhauser Verlag AG

Paper sent to revision: 04.08.2015.

Paper ready for publication: 15.09.2015. 